\title{
Petrophysical Investigations of Shale Gas Formations in Poland
}

ISSN: 2578-0255

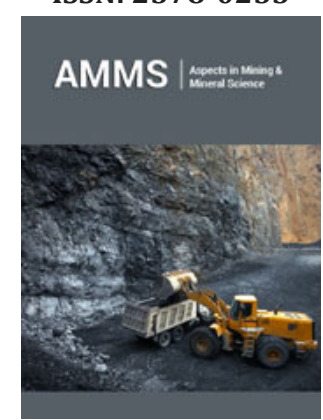

*Corresponding author: Jadwiga A Jarzyna, AGH University of Science and Technology and Faculty of Geology Geophysics and Environmental Protection, Department of Geophysics, Krakow, Poland

Submission: 海July 06, 2020

Published: 侮 August 12, 2020

Volume 5 - Issue 3

How to cite this article: Jarzyna J A, Krakowska-Madejska P I, Puskarczyk E, Wawrzyniak-Guz K. Petrophysical Investigations of Shale Gas Formations in Poland. Aspects Min Miner Sci. 5(3). AMMS. 000611. 2020.

DOI: 10.31031/AMMS.2020.05.000611

Copyright@ Jarzyna JA, This article is distributed under the terms of the Creative Commons Attribution 4.0 International License, which permits unrestricted use and redistribution provided that the original author and source are credited.

\section{Jarzyna J A*, Krakowska-Madejska P I, Puskarczyk E and Wawrzyniak-Guz K}

AGH University of Science and Technology, Faculty of Geology Geophysics and Environmental Protection, Department of Geophysics, Poland

\begin{abstract}
Results of laboratory experiments and well logging processing and interpretation are described to show the investigation trial realized on the Polish Silurian and Ordovician shale gas deposits in the Baltic Basin, north Poland. Standard and sophisticated laboratory methods of density, porosity, permeability, mineral composition and geochemical parameters measurements on rock samples were performed. Statistical methods were applied to standard, dipole sonic and geochemical well logs to limit the processed data without loss of useful petrophysical information, avoiding redundancy and doing the primary classification. The goal of this specific trial was to build petrophysical model of shale gas rocks taking into account low porosity, very low permeability, TOC equal at least $2 \mathrm{wt} . \%$ and organic matter as a kerogen and bitumen, free gas gathered in the rock matrix effective porosity and in secondary porosity. The unique model for the Polish shale gas formations is explained by age, depth of occurrence and mineral composition of the Silurian and Ordovician shales, different from those described in the literature.
\end{abstract}

Keywords: Silurian and Ordovician shale gas formation; Baltic basin; Poland

\section{Introduction}

Unconventional hydrocarbon deposits (shale oil and gas, tight gas, coal-bed-methaneCBM and gas hydrates) are very important components of the natural energy resources. They are under detailed investigations in many countries all over the world and intensity of the research works depends on economy state in the hydrocarbon prospecting industry and politics, which nowadays is mostly oriented to renewable energy resources. Poland, with relatively low resources of hydrocarbon, is extremely interested in detailed recognition of the Paleozoic shales with gas observed from the primary drillings in the Baltic, Podlasie and Lublin Basins as potential shale gas resources [1-5].

\section{Geological setting}

The Silurian and Ordovician shale formations in the north-eastern and central-eastern Poland are observed along the margin of the East European Platform. The analysis was focused on two formations in the Baltic Basin: Ordovician Sasino Formation (Sa Fm) and Jantar Member (Ja Mb) of the Silurian Pasłęk Formation as potential resources of unconventional hydrocarbons $[1,4,5]$. The discussed formations are composed of black, dark gray, and graygreenish bituminous shales. Average TOC values of Sa Fm and Ja Mb are 3.1 and 3.0 wt.\%, respectively. Depth of occurrence is between $2800-3200 \mathrm{~m}$.

\section{Materials and Methods}

The Silurian and Ordovician formations are heterogeneous due to geological, sedimentological, mineralogical, geochemical, and petrophysical parameters. Results of well logs suffer additionally from the influence of factors related to the construction of logging devices. So, combining the point type laboratory results and continuous well logging 
outcomes based on various physical basis are very important scaling platform in construction of static geological model before seismic data interpretation. Therefore, the methodology applied in these investigations was focused on realizing many laboratory measurements on the same part of the rock and then constructing the most probable relationships between them. Mutual relationships between parameters from well logging and crossrelations between lab and well origin variables were also included. The results illustrate the mutual relations between investigated variables and lithology, reservoir parameters, hydrocarbon production potential, and other factors used to characterize shale rock formation. List of the used laboratory methods comprises the following: mercury injection porosimetry, physical adsorption of nitrogen at $77 \mathrm{~K}, \mathrm{NMR}$ experiments, pressure decay permeability method and pulse decay permeability method for selected plugs, water immersion porosimetry with light kerosene immersion porosimetry [6], helium pycnometer, Rock-Eval pyrolysis, XRD analysis and micro-tomography imaging. From the other side all available well logs were included: GR, SGR-URAN, THOR, POTA, NPHI, RHOB, PE, LLD, LLS, XRMI, DT, DTP and DTS from dipole sonic device and results of the comprehensive interpretation of well logs as total and effective porosity, PHI and PHIE, respectively, volume of kerogen VKER, volume of shale VSH, volumes/mass of elements from geochemical log.

\section{Results}

Density and porosity turned out to be the critical petrophysical properties in shale gas formation characterization. Laboratory measurements of bulk, specific, grain, and material density in the mudstones of complicated structure revealed differences in their mineral composition and the presence of organic matter. Total and effective porosity values observed from laboratory measurements and well logging varied in the mudstone rocks with a thinly laminated macrostructure and high-tortuosity porous space microstructure. Density and porosity were measured in the laboratory using sophisticated methods, but the results only provided point information. In comparison, measurements recorded in continuous well logging were influenced by environmental conditions and the vertical resolution of logging devices. Creative combining these two types of results requires depth matching of laboratory measurements and vertical averaging of well logging outcomes, and this was used to construct mutual relationships resulting in detailed petrophysical characteristics (Figure 1) [1,2,7].
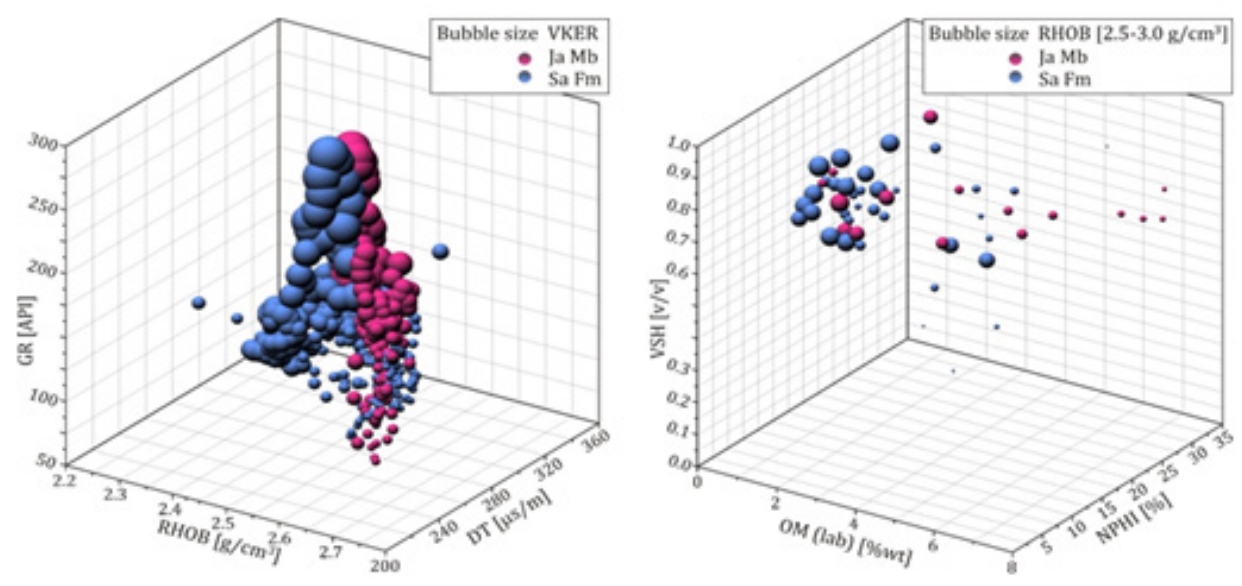

Figure 1: 3D illustration of mutual relationships between well logging results: GR, RHOB, DT, VKER, VSH and lab determined mass of organic matter OM in Sa Fm and Ja Mb.

\section{Conclusion}

Statistical methods revealed great heterogeneity of shale formations and abled primary classifications [8,9]. Depth matching of laboratory results and well logging outcomes was the basis for data upscaling. Sophisticated micro-tomography experiments showed complicated geometry of pore structure of shale rocks $[7,10]$. Extended density and porosity investigations helped in identification of gas presence in macro and micro pores [11]. Geochemical log results verified with the XRD analysis allowed mineral composition recognition to obtain reliable information on friability of shale rocks.

\section{Acknowledgment}

This study was financed by the National Centre for Research and Development, Warsaw, Poland, in the Blue Gas program project titled, "Methodology to determine sweet spots based on geochemical, petrophysical and geomechanical properties in connection with correlation of laboratory test with well logs and generation model 3D" (MWSSSG) Polskie Technologie dla Gazu Łupkowego (2013-2017). Access to data for the study was permitted by the Polish Oil and Gas Company, Warsaw, Poland.

\section{References}

1. Jarzyna J, Wawrzyniak Guz K (2017) Adaptation of the polish conditions of the methodologies of the sweet spots determination on the basis of correlation of well logging with drilled core samples: Methodology to determine sweet spots based on geochemical, petrophysical and geomechanical properties in connection with correlation of laboratory test with well logs and generation model 3D. Printed by GOLDRUK Wojciech Golachowski, p. 500.

2. Jarzyna JA, Bała M, Krakowska PI, Puskarczyk E, Strzępowicz A, et al. (2017) Shale gas in Poland. In: Hamid A Al Megren, Rashid H Altamimi (Eds.), Advances in natural gas emerging technologies, UK. 
3. Kiersnowski $H$ (2013) Geological environment of gas bearing shales. In: Nawrocki J (Ed.), Shale gas as seen by Polish Geological Survey. Polish Geological Institute-National Research Institute, Poland, pp. 26-31.

4. Poprawa P (2010) Shale gas potential of the lower palaeozoic complex in the Baltic and Lublin-Podlasie basins (Poland). Przegl Geolog 58(3): 226-249.

5. Podhalańska T (2003) Late ordovician to early silurian transition and the graptolites from ordovician/silurian boundary near the SW rim of the East European Craton (northern Poland). Series Geological Correlation 18: 165-172.

6. Topór T, Derkowski A, Kuila U, Fischer TB, McCarty DK (2016) Dual liquid porosimetry: A porosity measurement technique for oil-and gas-bearing shales. Fuel 183: 537-549.

7. Krakowska Madejska PI, Jarzyna JA (2020) Diverse scale data for shale gas formation description-why is digital shale rock model construction difficult? The polish silurian and ordovician rocks case. Minerals 10(108): 1-20.
8. Wawrzyniak Guz K, Puskarczyk E, Krakowska PI, Jarzyna JA (2016) Classification of polish shale gas formations from Baltic Basin, Poland based on well logging data by statistical methods. $16^{\text {th }}$ International Multidisciplinary Scientific Geo Conference 3: 761-768.

9. Puskarczyk E, Jarzyna JA, Wawrzyniak Guz K, Krakowska PI, Zych M (2019) Improved recognition of rock formation on the basis of well logging and laboratory experiments results using factor analysis. Acta Geophysica 67(6): 1809-1822.

10. Krakowska P (2019) Detailed parametrization of the pore space in tight clastic rocks from Poland based on laboratory measurement results. Acta Geophysica 67(6): 1765-1776.

11. Jarzyna JA, Czepirski L, Krakowska PI, Puskarczyk E, Szczurowski J, et al. (2017) Petrophysical model of Polish shale gas rocks on the basis of various laboratory experiments. Proceedings of the $79^{\text {th }}$ EAGE Conference \& Exhibition 2017: 1-5. 